\title{
A ALAVANCA ENERGÉTICA RUSSA: A Utilização do Setor de Petróleo e Gás como Instrumento Geopolítico
}

\author{
Pedro Henrique Miranda Gomes (PPGEST/INEST) ${ }^{1}$
}

RESUMO: Neste texto busca-se sistematizar o papel da indústria do petróleo e gás (P\&G) no fortalecimento geopolítico da Federação Russa no pós-Guerra Fria. A análise concentra-se nas ações tomadas pelo país a partir da chegada de Vladimir Putin ao poder, uma vez que a natureza corporativista de seu governo, baseada em uma "vertical do poder", favorece o uso do referido setor para fins geopolíticos. A motivação para a realização de artigo é contribuir com os estudos sistemáticos das iniciativas do Kremlin ao redor da alavanca energética de poder e as reações suscitadas por essas iniciativas nos outros atores da região. O nosso objetivo é caracterizar a variável "setor de petróleo e gás russo". Isso será realizado a partir de análise quantitativa no que diz respeito à verificação de elementos de aferição ligados à variável, como volumes de exportação, porém será também lançado mão da análise qualitativa. Resultados indicam três frentes de atuação central da grande estratégia russa no que tange o setor: Europa, China e estrangeiro próximo, a partir de projetos de construção de oleodutos, gasodutos e investimentos estratégicos em países parceiros.

Palavras-chave: Federação Russa; Geopolítica Energética; Petróleo e Gás.

\begin{abstract}
This text seeks to systematize the role of the oil and gas industry (P\&G) in the geopolitical strengthening of the Russian Federation in the postCold War period. The analysis focuses on the actions taken by the country after the arrival of Vladimir Putin to power, since the corporatist nature of his government, based on a "vertical of power", favors the use of the referred sector for geopolitical purposes. The motivation for writing an article is to contribute to the systematic studies of the Kremlin's initiatives around the energy lever of power and the reactions raised by these initiatives in other actors in the region. Our goal is to characterize the variable "Russian oil and gas sector". This will be carried out based on quantitative analysis with regard to the verification of measurement elements linked to the variable, such as export volumes, however, qualitative analysis will also be used. Results indicate three fronts of central action of the great Russian strategy with respect to the sector: Europe, China and close foreigners, based on projects for the construction of oil and gas pipelines and strategic investments in partner countries..
\end{abstract}

Keywords: Russian Federation. Energy Geopolitics. Oil and Gas. 1 Doutorando do Programa de Pós-Graduação em Estudos Estratégicos da Defesa e Segurança
(PPGEST/INEST) 


\section{Introdução}

Após a queda da URSS, é possível identificar uma distinção absoluta da política externa russa em dois períodos: na década de 90, sob a liderança de Yeltsin, e a partir de 2000, com os governos Putin-Medvedev. Ela sai de uma cooperação absoluta com o Ocidente e da aceitação do status quo estabelecido com o fim da bipolaridade, para uma política mais assertiva e independente, que busca contrabalancear o bloco ocidental, em especial no que tange aos países da OTAN.

A "era Putin" é marcada pelo estabelecimento de um sistema corporativista, que define a hierarquia e a orientação nas quais as estruturas política e econômica do Estado russo estão arranjadas. Dessa forma, o setor de petróleo e gás, que já era o setor econômico chave da federação, passa também a ser uma ferramenta estratégica na política internacional.

O que se busca entender no presente texto é de que forma o setor de P\&G russo se tornou um instrumento geopolítico. Nesse sentido, propomos uma pesquisa descritiva, a partir da caracterização da variável "setor de Petróleo e Gás russo". Uma vez realizado este esforço, almejamos concluir uma sistematização dos projetos estratégicos do Estado russo no setor de petróleo e gás, ilustrada nas tabelas 1, 2 e 3.

A análise quantitativa nos será útil na medida em que possamos lançar mão de elementos quantificáveis no que diz respeito à verificação da variável independente, a presença do setor. Para tal, será essencial o uso da base de dados da Eurostat sobre a importação de hidrocarbonetos, bem como dados advindos do governo russo acerca dos destinos e volumes de exportação, dados acerca da construção de dutos de transporte de hidrocarbonetos, entre outros. Por outro lado, a análise qualitativa estará também presente no texto, na medida em que lançaremos mão de literatura especializada que se ocupou do tema anteriormente. Neste sentido, contamos com uma coletânea sobretudo de autores francófonos (YAKEMTCHOUK, 2008; RADVANYI; LARUELLE, 2016; PIATIGORSKY; SAPIR, 2009, entre outros) que conduziram análises descritivas e críticas em diferentes esferas da atuação do Estado russo. 


\section{Universidade Federal Fluminense \\ Instituto de Estudos Estratégicos}

A divisão do trabalho é realizada, portanto, de modo que em seguida a esta introdução haverá uma outra para considerações iniciais a respeito do modelo de governo putiniano. Em seguida, aborda-se o mecanismo de poder da alavanca energética, a partir de subseções dedicadas a cada região específica de atuação desse mecanismo. Finalmente haverá uma seção referente aos resultados apresentados ao que se seguem as considerações finais.

\section{1 - O Corporativismo À La Russe}

Diante das particularidades do modelo putiniano ocorreu 0 estabelecimento de uma vertical do poder, que perfila a estrutura política e econômica da federação russa, criando uma linha de transmissão mais rígida que busca adequar os setores estratégicos a um projeto único para o país. Como resultado, as empresas de combustível passam a ser mais claramente utilizadas como instrumentos efetivos para a busca dos seus interesses geopolíticos. Esses instrumentos não estavam completamente ausentes da ação externa do governo Yeltsin (que chegou, inclusive, a construir o gasoduto Yamal-Europa, que inicia o contorno da Ucrânia), mas seu uso era mais restrito, devido à postura descentralizadora do governo, que, ao abrir mão dos ativos e mecanismos de controle governamental do setor, perde capacidade de acioná-lo imediatamente ${ }^{2}$.

A ferramenta energética tem sua atuação dividida em duas ações estratégicas principais: por um lado, em esforços de reforçar (e, atualmente, recuperar) a influência russa no chamado "estrangeiro próximo", composto pelas ex-repúblicas soviéticas; pelo outro, em projetos que visam reduzir a vulnerabilidade russa no comércio exterior e reforçar sua posição geopolítica frente aos seus parceiros comerciais - diversificando os destinos dos hidrocarbonetos e buscando aumentar a dependência destes frente ao país eslavo. Há, ainda, uma atuação das empresas energéticas com Investimentos Diretos Externos (IDE's) que condizem com os interesses da política externa russa.

\footnotetext{
2 Para maior aprofundamento nas particularidades dos dois modelos de governança, ver Gomes (2018).
} 
Neste complexo de interesses, cabe ressaltar a importância que recai na região da Ásia central - com destaque para o Mar Cáspio - localizada no centro de três grandes atores de interesses conflitantes no que diz respeito a recursos energéticos. Se, no século XIX, a disputa geopolítica entre Inglaterra e Rússia na região recebia o nome de "o grande jogo", a questão energética leva à reedição do fenômeno, desta vez expandido pela participação da China e da Europa como um todo (PIATIGORSKY; SAPIR, 2009).

Entretanto, não se pode entender esta vertical do poder como uma pura extensão do governo, desprovida de quaisquer interesses próprios. Ao se referir à companhia Gazprom, Piatigorsky e Sapir fazem as seguintes considerações:

O gigante do gás russo é incontestavelmente um instrumento
importante nas mãos do poder. mas ele não é apenas isso. A
existência de uma estratégia autônoma, definida pelos
interesses próprios da companhia é indubitável. O que faz ao
mesmo tempo a complexidade e a eficácia da estratégia russa
no domínio da energia reside justamente nessa combinação
entre interesses de Estado e os das grandes companhias que,
certamente, o servem e dependem dele, mas que também
sabem fazer valer suas lógicas industriais para evitar uma
instrumentalização muito estreita. (2009, p. 178-179, tradução
nossa).

Ainda assim, o alcance da alavanca energética é politicamente substancial, levando Mongrenier e Thom (2016) a descrever o país como uma "energocracia". A ação das empresas se divide em três frentes: Europa, da qual Moscou busca reduzir a dependência, sendo o continente o principal destino para as exportações energéticas (GOMES, 2018); China e mercado sul-asiático, cujo forte crescimento o faz aparecer como alternativa ao Ocidente; e estrangeiro próximo, que, através das redes de distribuição de hidrocarbonetos e IDE's, o Kremlin tenta manter sob seu controle. A este grupo adicionam-se as atividades das companhias em países aliados ou estratégicos para Moscou. As ações dividem-se, ainda em duas principais: IDE's e construção de uma infraestrutura de fornecimento de combustível, possibilitando novas rotas aos principais destinos. 


\section{2 - As Frentes de Utilização da Alavanca Energética}

\section{1 - A Europa}

O Mar Cáspio dispõe de importantes reservas tanto offshore quanto na região continental litoral. Estima-se que que contenha 48 bilhões de barris de petróleo e 8.7 trilhões de metros cúbicos de gás em reservas provadas ou prováveis (STRATFOR, 2014). Ele está no epicentro da reedição do "Grande Jogo" geopolítico da região, por ser disputado entre Europa, Rússia e China, uma vez que um encaminhamento direto das reservas aí presentes pode significar uma redução da dependência tanto europeia quanto chinesa do petróleo russo. Soma-se a isso a influência e financiamento dos EUA, que, ao lado da Inglaterra, vê como desestabilizante o domínio russo (ou pior, iraniano) sobre as reservas, de modo que apoia a construção de novas rotas de fornecimento à $\operatorname{Europa}^{3}$ (YERGIN, 2014) .

Se nas décadas de 60 e 70 a região era vista como esgotada ou difícil tecnologicamente de ser explorada, Baku, no Azerbaijão, tem um renascimento na década de 90 com o desenvolvimento do campo Shah Deniz, em uma operação que foi chamada pelo presidente do país de "o acordo do século" (YERGIN, 2014). Na mesma década de 90 foram iniciados os projetos para levar os hidrocarbonetos do país à Europa, aproveitando-se da sua posição estratégia na margem ocidental do Mar Cáspio.

Para lidar com o excesso de fluxo de navios petroleiros no Bósforo, o projeto para transporte de petróleo de Baku seguiria o trajeto Baku-TbilisiCeyhan, que deu nome ao oleoduto (BTC - Tabela 2), o qual está operacional desde 2006 e atualmente tem capacidade de 59,8 milhões de toneladas por ano (BRITISH PETROLEUM, 2018b). O Azerbaijão busca, dessa forma, reduzir sua dependência da Rússia, fornecendo petróleo por esta rota, enquanto mantém transporte também à Rússia (YAKEMTCHOUK, 2008). Além disso, foi esquematizado um plano do Ocidente de formar um corredor de gás, que ficou

\footnotetext{
3 A opção pela diversificação do fornecimento que evitasse o controle russo era evidente sobretudo após ter ficado clara a dependência global dos hidrocarbonetos árabes durante a Guerra do Golfo. Era preciso, portanto, agir no sentido de diversificar a oferta para este mercado, em especial no que diz respeito ao fornecimento a um aliado estratégico.
} 


\section{Revista Brasileira de Estudos Estratégicos}

REST V13 No 25 Jan-Jun 2021

conhecido como projeto Nabucco, o qual encaminharia gás natural de Baku à Europa. Contudo, o projeto, que seguiria até o centro da Europa, se tornou inviável economicamente (devido a custos de produção e concorrência do projeto russo South Stream), dando lugar a projetos concorrentes.

Desta forma, o projeto Nabucco dá lugar à nova iniciativa europeia, de construção do Southern Gas Corridor, uma série de projetos que levariam gás do Mar Cáspio à Europa. O primeiro é o South Caucasus Pipeline (SCP), que segue o caminho do BTC, do Azerbaijão à fronteira entre Turquia e Geórgia ${ }^{4}$, seguido pelo TANAP, que atravessa a Turquia e foi posto em operação em 2018. A parte final, o Trans Adriatic Pipeline (TAP) está com 80,7\% da sua construção realizada, e deve terminar de ligar o Mar Cáspio à Itália (TRANS ADRIATIC PIPELINE, 2018). Há, ainda, o plano para expandir esse desenho, construindo um gasoduto que atravesse o Cáspio, chegando ao Turcomenistão, o TransCaspian Pipeline (TPC), sendo facilitado pelo acordo obtido acerca do status do mar. Esta expansão pode contar, ainda, com a participação do Irã, dependendo do rumo que tomar as relações do país com o Ocidente (REGNUM, 2018). Inicialmente, aproximadamente 10 bcm/y (billion cubic meters/ year) de gás correrão por ano pelo corredor. Contudo, a UE pretende aumentar este número para 80 a 100 bcm/y no futuro (EUROPEAN COMISSION, 2018).

Por sua vez, a Rússia busca garantir sua posição no mercado europeu. É com isso em mente que Gazprom e Lukoil desenvolvem suas estratégias com base na compra de infraestrutura de energia na Europa (SCHUTTE, 2011). Foi nesse contexto, em 2009, que entrou em vigor o "terceiro pacote energético europeu", dispondo da "cláusula de terceiro país" (que ficou conhecida como Cláusula Gazprom), que estabelece que companhias de países não europeus deverão entrar em acordo com a autoridade reguladora e dar evidências de que sua participação na infraestrutura energética não colocará em risco a segurança energética tanto do país em questão quanto da União Europeia (KHODAKOVSKYY, 2013-2014).

A lei teve o efeito prático de barrar a construção da alternativa russa aos projetos de corredores energéticos ocidentais. Moscou pretendia disputar o

\footnotetext{
4 Posto em operação em 2006, com capacidade inicial de 7,4 bcm, que logo foram expandidos para 23,4 bcm, e tem capacidade para nova expansão até 31 bcm (SOUTHERN GAS CORRIDOR, 2018).
} 


\section{Universidade Federal Fluminense \\ Instituto de Estudos Estratégicos}

fornecimento ao sul europeu lançando mão, em 2007, do South Stream, que teria capacidade de $63 \mathrm{bcm}$ e atravessaria o mar negro até a Turquia, de onde enviaria gás para a Europa (MONGRENIER; THOM, 2016). Planejava-se que 0 tubo se estendesse até a Itália passando por Bulgária, Sérvia, Hungria e Eslovênia. Com a construção já em andamento, o projeto foi cancelado em dezembro de 2014 por objeções da UE, acolhidas pela Bulgária (HYDROCARBONS TECHNOLOGY, 2018).

Em substituição, o Kremlin inicia o projeto TurkStream, que atravessa o Mar Negro diretamente até a sessão europeia da Turquia. O projeto havia sido paralisado por Moscou em 2015, em resposta ao abatimento de um caça russo pelas forças armadas turcas, porém a normalização das relações entre os dois países possibilitou a retomada do projeto, que tem capacidade planejada de 31,5 bcm por ano e tem o início das atividades previsto para o final de 2019 (GAZPROM, 2018). O TurkStream complementa o fornecimento que já é realizado à Turquia pelo Blue Stream (10 bcm/yr), e disputa o mercado europeu com os hidrocarbonetos do SGC. A rota pode, ainda, expandir-se e recuperar a rota que foi cancelada junto ao South Stream, o que foi confirmado pelo primeiroministro búlgaro em maio de 2018 (ZARUBIN, 2018).

Além dos projetos de gasodutos, a Rússia disputa o mercado europeu com o fornecimento de Gás Natural Liquefeito (GNL). Plantas de produção em Sakhalin II e Yamal planejam competir com o assédio estadunidense, que, com uma produção em franca ascensão, busca substituir o fornecimento russo para a Europa. Essa opção, contudo, ainda não é economicamente viável, e o fornecimento americano segue sendo diminuto (GOMES, 2018).

\section{2 - O "Estrangeiro Próximo"}

O espaço das ex-repúblicas soviéticas é justamente aquele onde Moscou parece dispor de poder mais direto, ainda que essa influência esteja sendo disputada abertamente pelos outros atores do "grande jogo", o que permite a esta região praticar uma diplomacia multivetorial (MONGRENIER; THOM, 2016). Ao lado dos conflitos congelados, a política de preços de gás, construção de gasodutos e IDE's da indústria energética são mecanismos do Kremlin visando consolidar sua zona de influência. 


\section{Revista Brasileira de Estudos Estratégicos \\ REST V13 No 25 Jan-Jun 2021}

É buscando esta consolidação que Moscou define uma política de preços baixos para o estrangeiro próximo. No projeto geopolítico russo (que atualmente dialoga com o Eurasianismo ${ }^{5}$ ), a Ucrânia é parte essencial, tanto de um ponto de vista simbólico quanto prático ${ }^{6}$. Por essa razão, os termos do fornecimento de gás acordados em 1995 Ihe foram amplamente favoráveis (U\$ 50,00 por 1000 $\left.\mathrm{m}^{3}\right)$.

Contudo, com as revoluções coloridas, o Kremlin anuncia a modificação da política russa de gás frente aos Estados do "estrangeiro próximo" e a Gazprom cobra junto ao governo de Kiev o preço de 130 dólares por $1000 \mathrm{~m}^{3}$. No inverno seguinte, a Gazprom viria a cobrar 235 dólares à Geórgia, no lugar dos 110 de até então (YAKEMTCHOUK, 2008). Ambos os países recusaram os novos preços e tiveram seus fornecimentos interrompidos. No caso ucraniano, como a vasta maioria das importações europeias transitavam pela Ucrânia, os ucranianos se serviram diretamente da quantidade direcionada à EU, gerando uma crise que teve fim com um novo acordo de 95 dólares. Já a Geórgia sofreu, além da interrupção no fornecimento, com a construção de um gasoduto russo que passou a levar gás russo diretamente à Ossétia do Sul, sem passar pelas estruturas georgianas (YAKEMTCHOUK, 2008). Se trata do gasoduto "Dzuarikau-Tsinval", que em 2010 assinou um acordo de fornecimento de gás à região até 2029 (GASPROM, 2017b). Esse movimento pressiona ainda mais o governo georgiano, que vê a cooperação entre uma região separatista e Moscou crescer.

Visto a importância da Ucrânia, fica claro que os projetos de tubos para diversificar as rotas em direção à Europa também estão intencionados, por um lado, em reduzir a dependência em relação ao vizinho eslavo ao criar rotas que o contornam e, pelo outro, em desvalorizá-lo frente à EU, reduzindo seu campo de ação e aumentando a pressão para um realinhamento com Moscou

\footnotetext{
${ }^{5}$ O Eurasianismo é uma filosofia política que prevê uma multipolaridade de civilizações, partindo de uma base anti-imperialista e anti-modernista e de uma perspectiva russa, entendendo a particularidade do país eslavo, que o separa da civilização europeia e dos povos asiáticos (DUGIN, 2014). Nesta perspectiva, a Rússia deveria reorganizar o território da Eurásia, o que implica restabelecer o controle sobre a zona das ex-repúblicas soviéticas, e absorver espaços ainda além destas, buscando seus aliados naturais, que seriam países continentais - como Alemanha e Irã - contra adversários naturais, entendidos como "Estados marítimos" - EUA e Reino Unido (MARCU, 2007).

$6 \mathrm{O}$ país permanecia sendo um parceiro essencial à Rússia em várias esferas, inclusive no complexo militarindustrial. Ademais, o país é como uma porta energética para o Ocidente, com $80 \%$ das exportações russas à Europa passando pelo país em meados da década de 2000 (YAKEMTCHOUK, 2008).
} 


\section{Universidade Federal Fluminense \\ Instituto de Estudos Estratégicos}

(MONGRENIER; THOM, 2016). Essa é a lógica principal da construção do Nord Stream, em 2011, e seu gêmeo paralelo, Nord Stream 2, de $55 \mathrm{bcm} / \mathrm{yr}$ de capacidade cada, seguindo uma rota direta através do Mar Báltico até a Alemanha. O Nord Stream 2 ainda não foi construído, e enfrenta dura resistência dos EUA e do leste europeu, que denunciam sua motivação política ${ }^{7}$.

A intenção de excluir a Ucrânia como país de trânsito, ainda que temporariamente, tem se tornado cada vez mais evidente. Após um processo de solução de controvérsia desfavorável à Moscou entre a Gazprom e a análoga ucraniana Naftogaz, o fornecimento de gás à Ucrânia começou a ser cortado (GORDONUA, 2018) e, no final de março, iniciaram-se as negociações para cancelamento dos contratos de fornecimento de gás entre as duas partes (VESTI, 2018). Se o cancelamento de fato ocorrer, o impacto na economia ucraniana será alto, e resta saber se o Ocidente estará disposto a socorrê-la.

O Central Pipeline Consortium (CPC - Tabela 2), um oleoduto ligando o Cazaquistão à Rússia, foi concluído em 2001 e se apresenta como uma alternativa ao BTC, uma vez que o CPC também funciona como uma ponte energética entre o Cáspio e a Europa. Comparando, tanto uma rota quanto a outra tem fragilidades: O BTC não dispõe de um oleoduto que atravesse 0 Cáspio, estando limitado à banda ocidental, enquanto o CPC, que termina em Novossibirsk, realiza uma rota que dispõe dos hidrocarbonetos tanto do Cazaquistão, quanto do Azerbaijão (que também possui oleoduto levando a Novossibirsk), mas já opera acima de sua capacidade (DELLECKER, 2008).

No que diz respeito ao gás do Cáspio, a Rússia dispõe de fornecimento graças ao sistema "Central Asia-Center" (CAC), construído em 1969 (KARAKALPAKSTAN BLOG, 2017). Graças à posição de monopólio, a Gazprom comprava gás Cazaque, uzbeque e turcomeno a um preço inferior ao do mercado internacional (70 dólares por $1000 \mathrm{~m}^{3}$ em 2005, 130 a 150 dólares em 2007) e revendia a um preço claramente superior aos Estados da União Europeia ou à Ucrânia (YAKEMTCHOUK). Com a precipitação de outros atores do "grande jogo" na região (um projeto de gasoduto para a China e a perspectiva de um

\footnotetext{
7 Em fevereiro de 2018, o premiê polonês declarou que, com o Nord Stream 2, "Putin poderá fazer com a Ucrânia o que quiser”. No que tange o leste europeu, uma das preocupações da Polônia é que a Rússia forneça gás diretamente à Alemanha e corte o suprimento da região (NEFTEGAZ, 2018).
} 
"gasoduto transcaspiano" a partir de Baku), a região vê o aumento da sua área de ação e Moscou se vê obrigada a nivelar os preços pagos já no final da década.

Em um esforço para garantir uma fatia importante do gás da Ásia central, Putin firmou acordos para expandir o fornecimento através do CAC. Em 2007, Putin e os presidentes do Cazaquistão e Turcomenistão assinaram um acordo para a construção de um novo gasoduto que aumentaria sensivelmente as exportações à Europa via Rússia (Nygren, 2009). O gasoduto iria do Turcomenistão à Rússia via Cazaquistão, seguindo a costa oriental do Cáspio, paralelo a uma estrutura menor já existente, antes de conectar-se ao sistema de gasodutos russos com destino à Europa (NYGREN, 2009). Com um novo gasoduto para incluir o Uzbequistão no sistema, o Kremlin conseguiu uma fatia importante do gás da região e reduziu a viabilidade da eventual construção do TCP.

As operações da Gazprom na Armênia também são estratégicas. Em troca de um preço fixo de 110 dólares por $1000 \mathrm{~m}^{3}$, a Gazprom aumentou sua participação de $45 \%$ a $80 \%$ da ArmRosGazprom em 2006 (KOMMERSANT, 2006), e, em 2013, passaria a deter 100\% (RBC, 2014). Esta é a empresa que possui os gasodutos do país, bem como o status de principal contratada para a construção do segundo ramo do gasoduto Irã-Armênia. Isso complica o acesso iraniano ao mercado Europeu e põe a Gazprom em posição de força na negociação com o Irã, que aceita a participação da companhia no campo de Pars-sul (Irã), em seguida ao acordo com a Armênia (PIATIGORSKY; SAPIR, 2009).

O interesse russo nisto, além da participação na promissora produção iraniana, é evitar que o gás iraniano venha a atravessar a Armênia e integrar o mercado europeu, competindo com o combustível russo. A saída encontrada por Moscou foi o esforço de construção de um gasoduto que escoe a produção iraniana do Pars-Sul para o crescente mercado do sul asiático, através do chamado "gasoduto da paz" (IP), seguindo a rota Irã-Paquistão-Índia. Através da Gazprom, Moscou tem negociado com os países envolvidos; porém, a 


\section{Universidade Federal Fluminense \\ Instituto de Estudos Estratégicos}

indefinição acerca das sanções do Ocidente contra o Irã entrava o projeto ${ }^{8}$, o que é agravado pela saída dos EUA do acordo nuclear com o país persa.

\section{3- A China}

O forte crescimento econômico chinês e o aumento da demanda por energia que o acompanha faz com que a China recorra crescentemente ao mercado global de petróleo e gás para satisfazer suas necessidades internas (GOMES, 2018). O país asiático tem sido, por si só, um dos fatores fundamentais para o aumento do preço do petróleo da década de 2000 (YERGIN, 2014). Sendo um setor estratégico, busca-se aumentar a segurança energética do país, de modo a não depender de fontes únicas de energia. A Rússia, em posição estratégica entre a Europa e a Ásia aparece em posição privilegiada para suprir essa demanda. Moscou busca ainda diversificar suas exportações de hidrocarbonetos, e entra no mercado asiático com esta intenção.

Em 2006 inicia-se a construção do oleoduto East-Siberia Pacific Ocean (ESPO - Tabela 2), que leva petróleo da Sibéria oriental até o Pacífico. O objetivo de Moscou era se beneficiar da concorrência entre os grandes consumidores regionais (Japão, Coréia, China, e outros), porém a China obteve a construção de uma derivação do ESPO desde Skovorodino até Daqing, inaugurado em 2010, e que acabou ganhando espaço em relação ao projeto principal, assegurando $6 \%$ das importações chinesas de petróleo (MONGRENIER; THOM, 2016). Isso aumenta ainda mais a importância do desenvolvimento da usina Sakhalin II, de produção de LNG, para atender ao mercado do sudeste asiático.

Para diversificar as fontes, também em 2006 é inaugurado o oleoduto Cazaquistão-China (Tabela 2), com capacidade de 10 milhões de toneladas por ano. No ano seguinte, a cooperação energética com a Ásia Central é ainda reforçada com o início da construção do gasoduto Central Asia-China, que sai da fronteira entre Uzbequistão e Turcomenistão e tem a capacidade de levar 40 $\mathrm{bcm} / \mathrm{yr}$ ao Xinjiang Chinês. A presença chinesa na região deixa clara a formação

\footnotetext{
8 Enquanto a sessão iraniana está completa, o Paquistão está atrasado na sua parte desde 2014 e alega que o gás iraniano ainda é afetado pelas sanções (NEFTEGAZ, 2017).
} 
de mais uma rota de abastecimento ao país asiático que fará parte da nova rota da seda9: do Cáspio ao Xinjiang, um grande Turkestão energético parece tomar forma (MONGRENIER; THOM, 2016). Este corredor e a necessidade do Kremlin de voltar-se para a China após a crise de 2014, seguida pelas sanções europeias e americanas, põem a China em posição de força nas negociações de fornecimento de gás natural. Nessas condições, em 2014 Putin assina um contrato de fornecimento de gás, de modo que a partir de 2018 um volume de 38 bcm/ano será fornecido à China por três décadas pelo "Força da Sibéria".

\section{4 - Investimentos Estratégicos}

\section{Figura 2 - Programa de Investimento 2014-2016 (Rosneft) 2014-2016 INVESTMENT PROGRAM RUB BLN}

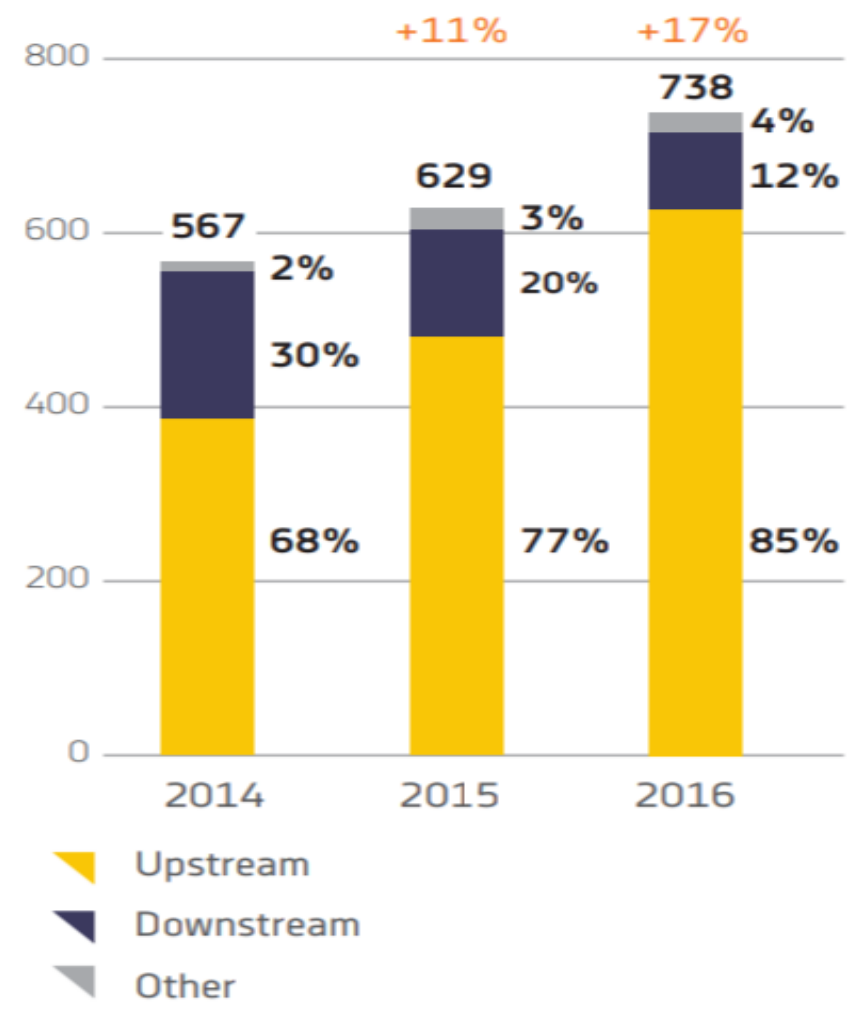

Fonte: Rosneft.

\footnotetext{
9 A nova rota da seda, como ficou conhecida a "Belt and Road Iniciative", é uma iniciativa de fortalecimento de infraestrutura, comércio e fluxos de investimento entre a China e uma série de outros países de Europa, Ásia e África (WORLD BANK, 2018).
} 


\section{Universidade Federal Fluminense \\ Instituto de Estudos Estratégicos}

Em artigo de fevereiro de 2018, Chow e Stanley (2018) defendem a existência de uma série de projetos e atividades por parte principalmente da Rosneft que ilustram o uso da companhia como um instrumento da política externa russa, o que fica mais claro a partir dos choques gêmeos da queda dos preços do petróleo e das sanções impostas à Moscou em 2014. Sua lógica central é que uma companhia "normal" reduziria suas atividades, equilibraria a folha de pagamentos e esperaria por condições externas favoráveis ${ }^{10}$. A Rosneft, por outro lado, expandiu sua atividade internacionalmente, como se pode ver na figura 2.

Entre os investimentos estratégicos mencionados estão: (1) o acordo de "armas-por-petróleo", em 2006, e o apoio, tanto do governo russo quanto da Rosneft à Maduro, que precisariam ter um retorno astronômico para compensar pelo risco de investimento na Venezuela em crise; (2) o acordo de parceria em "projetos estratégicos" no valor de até U\$ 30 bilhões assinado entre Rosneft e a sua análoga iraniana, com a presença de Putin, enquanto era concedido à Rússia acesso a uma base aérea iraniana; (3) projetos no Iraque ligados à aquisição, em 2016, da companhia Bashneft, o que é visto como uma intenção de se tornar um ator-chave na reconstrução da indústria de petróleo e gás na região ${ }^{11}$, o que ainda solidifica a posição russa de fornecedor preeminente de energia à Turquia, a qual é uma aliada problemática da OTAN; e (4) o fortalecimento político entre o Kremlin e facções que disputam o governo da Líbia, com a intenção de adquirir uma base naval e de colocar a Rosneft no país, que tem as maiores reservas de petróleo africano, posicionado estrategicamente para fornecer gás natural à Europa.

A interpretação dos autores está correta, porém é preciso evitar simplificações acerca da natureza das empresas da estrutura desenhada por Putin. A Rosneft não pode ser comparada a uma empresa "normal", pois ela não o é, nem do ponto de vista da tomada de decisões, nem da fonte de capital. A ação das campeãs nacionais estatais baseia-se em uma confluência de

\footnotetext{
10 Isso de fato ocorreu, e neste período o cenário da indústria energética foi de grande corte nos investimentos projetados em todos os níveis da cadeia (LINS, ET AL., 2015)

11 Isso se ilustra no acordo assinado em janeiro de 2018, segundo o qual a Rússia terá direitos exclusivos de produção de petróleo e gás na Síria (KATONA, 2018).
} 


\section{Revista Brasileira de Estudos Estratégicos}

REST V13 No 25 Jan-Jun 2021

interesses entre empresa e Estado (que não é unilateral) e a percepção de risco é alterada, uma vez que a companhia tem o próprio Estado como fiador. As atividades da Rosneft descritas acima justificam-se, portanto, por esta confluência de interesses: agia estrategicamente em benefício do Kremlin ao mesmo tempo que adquiria ativos produtivos (upstream) a baixo custo em um momento em que seus competidores estavam estáticos, abrindo mão de grandes fatias do mercado.

\section{3 - RESULTADOS}

Uma vez apresentados os mecanismos dos quais dispõe o país eslavo para instrumentalizar a sua indústria energética, dispomos de elementos suficientes para indicar os principais caminhos seguidos pela Rússia para instrumentalizar o seu setor de combustíveis. Sistematizamos tais esforços a partir das tabelas 1, 2 e 3 :

Tabela 1- Projetos de Gasodutos

\begin{tabular}{|c|c|c|c|c|}
\hline \multicolumn{5}{|c|}{ Gasodutos } \\
\hline Nome & $\begin{array}{l}\text { Capacidade } \\
\text { (bcm/yr) }\end{array}$ & $\begin{array}{c}\text { Expansão } \\
\text { (bcm/yr) }\end{array}$ & Ano (status) & Países \\
\hline \multicolumn{5}{|c|}{ SGC (Southern Gas Corridor) } \\
\hline SCP (South Caucasus Pipeline) & 7,4 & $23,4-31^{*}$ & 2006 & $\begin{array}{c}\text { Azerbaijão } \\
\text { Geórgia }\end{array}$ \\
\hline TANAP & $\begin{array}{c}16 \\
\text { (6-TUR; 10- } \\
\text { UE) }\end{array}$ & $\begin{array}{l}24(2023)- \\
31(2026)^{\star *}\end{array}$ & 2018 & Turquia \\
\hline TAP & 10 & 20 & $\begin{array}{c}\text { em construção } \\
(93 \%)\end{array}$ & $\begin{array}{c}\text { Grécia } \\
\text { Albânia } \\
\text { Itália }\end{array}$ \\
\hline TCP (Transcaspian Pipeline) & - & - & em planejamento & $\begin{array}{c}\text { Turcomenistão } \\
\text { Azerbaijão }\end{array}$ \\
\hline \multicolumn{5}{|c|}{ Outros Gasodutos para Europa } \\
\hline \multicolumn{5}{|l|}{ NABUCCO (Cancelado) } \\
\hline South Stream (Cancelado) & 63 & - & $\begin{array}{c}2007 \\
\text { (anunciado) }\end{array}$ & $\begin{array}{c}\text { Rússia } \\
\text { Bulgária } \\
\text { Sérbia }\end{array}$ \\
\hline
\end{tabular}




\section{Universidade Federal Fluminense}

Instituto de Estudos Estratégicos

\begin{tabular}{|l|c|c|c|c|} 
& & & & outros \\
\hline Yamal-Europa & 32.9 & - & $\begin{array}{c}1994- \\
\text { Rronto em 1999 }\end{array}$ & $\begin{array}{c}\text { Belo-Rússia } \\
\text { Polônia } \\
\text { Alemanha }\end{array}$ \\
\hline Brotherhood & 28 & 100 & $\begin{array}{c}\text { Ucrânia } \\
\text { Chéquia } \\
\text { (pronto em 1983) }\end{array}$ & $\begin{array}{c}\text { Eslováquia } \\
\text { Austria } \\
\text { Rússia }\end{array}$ \\
\hline Turkish Stream & 31,5 & - & $\begin{array}{c}2014- \\
\text { (Pronto em 2020) }\end{array}$ & $\begin{array}{c}\text { Rússia } \\
\text { Turquia }\end{array}$ \\
\hline Nord Stream & 55 & - & $\begin{array}{c}\text { Rússia } \\
\text { Alemanha }\end{array}$ \\
\hline Nord Stream 2 & 55 & - & $\begin{array}{c}\text { Rússia } \\
\text { (acordos de } \\
\text { financiamento) }\end{array}$ & \begin{tabular}{c} 
Alemanha \\
\hline
\end{tabular} \\
\hline
\end{tabular}

\begin{tabular}{|c|c|c|c|c|}
\hline \multicolumn{5}{|c|}{ Gasodutos para a China } \\
\hline \multirow{2}{*}{ Power of Siberia } & \multirow{2}{*}{38} & \multirow{2}{*}{ - } & \multirow{2}{*}{$\begin{array}{c}2014 \\
\text { (acordo) }\end{array}$} & Rússia \\
\hline & & & & China \\
\hline \multirow{4}{*}{ Central Asia-China gas pipeline } & \multirow{4}{*}{40} & \multirow{4}{*}{-} & \multirow{4}{*}{$\begin{array}{c}2007 \\
\text { (construção) }\end{array}$} & Turcomenistão \\
\hline & & & & Uzbequistão, \\
\hline & & & & Cazaquistão \\
\hline & & & & China \\
\hline \multicolumn{5}{|c|}{ Outros Gasodutos } \\
\hline \multirow{2}{*}{ IP (Irã-Paquistão) } & \multirow{2}{*}{7,6} & \multirow{2}{*}{10} & \multirow{2}{*}{2010} & Irã \\
\hline & & & & Paquistão \\
\hline \multirow{3}{*}{ Central Asia-Center (CAC) } & \multirow{3}{*}{50} & \multirow{3}{*}{80} & \multirow{3}{*}{$\begin{array}{c}1969 \\
\text { ampliado em } 2009\end{array}$} & Turcomenistão \\
\hline & & & & Cazaquistão \\
\hline & & & & Rússia \\
\hline \multirow{2}{*}{ Blue Stream } & \multirow{2}{*}{10} & \multirow{2}{*}{ - } & \multirow{2}{*}{2002} & Rússia \\
\hline & & & & Turquia \\
\hline Dzuarikau-Tsinval & 0,3 & - & 2010 & $\begin{array}{c}\text { Rússia } \\
\text { Ossétia do Sul }\end{array}$ \\
\hline
\end{tabular}

Fonte: BP; Hydrocarbons Technology; Gazprom; Neftegaz; TANAP; Trans Adrialic Pipeline; le figaro; Ögütçü (2006); Dellecker (2008). Energy base.

* Uma expansão do SCP foi realizada e começou a operar em junho de 2018. Espera-se que alcance 23,4 $\mathrm{bcm} / \mathrm{yr}$. Se necessário, uma nova expansão pode ser realizada, e a capacidade da rota pode alcançar 31 $\mathrm{bcm} / \mathrm{yr}$.

${ }^{* *}$ A capacidade planejada atual do TANAP é de $16 \mathrm{bcm}$, mas a capacidade para o ano de 2023 sobe para $24 \mathrm{bcm}$, e, em 2026, para $31 \mathrm{bcm}$. 
Tabela 2 - Projetos de Oleodutos

\begin{tabular}{|l|c|c|c|c|}
\hline \multicolumn{1}{|c|}{ Oleodutos } \\
\hline Nome & $\begin{array}{c}\text { Capacidade } \\
\text { (ton/yr) }\end{array}$ & $\begin{array}{c}\text { Expansão } \\
\text { (bcm/yr) }\end{array}$ & $\begin{array}{c}\text { Ano } \\
\text { (status) }\end{array}$ & Países \\
\hline BTC (Baku-Tiblisi-Ceyhan) & $59,8 \mathrm{mi}$ & - & 2006 & $\begin{array}{c}\text { Azerbaijão } \\
\text { Geórgia } \\
\text { Turquia }\end{array}$ \\
\hline Cazaquistão-China & $10 \mathrm{mi}$ & - & 2006 & $\begin{array}{c}\text { Cazaquistão } \\
\text { China }\end{array}$ \\
\hline Central Pipeline Consortium (CPC) & $43 \mathrm{mi}$ & - & 2001 & $\begin{array}{c}\text { Russia } \\
\text { Cazaquistão }\end{array}$ \\
\hline ESPO & $58 \mathrm{mi}$ & - & $\begin{array}{c}2006 \\
\text { (início da } \\
\text { construção) }\end{array}$ & Rússia \\
\hline
\end{tabular}

Fonte: BP; Hydrocarbons Technology; Gazprom; Neftegaz; TANAP; Trans Adrialic Pipeline; le figaro; Ögütçü (2006); Dellecker (2008). Energy base.

\section{Tabela 3 - Investimentos Estratégicos}

\begin{tabular}{|c|c|c|}
\hline \multicolumn{3}{|c|}{ Investimentos Estratégicos } \\
\hline País & Natureza & Ano \\
\hline Venezuela & $\begin{array}{l}\text { Acordo armas-por-petróleo, acesso às } \\
\text { reservas venezuelanas e apoio ao regime }\end{array}$ & $2006-?$ \\
\hline Irã & $\begin{array}{l}\text { Desenvolvimento de poços, estratégia } \\
\text { de direcionar o escoamento para o sul, } \\
\text { acesso a base aérea }\end{array}$ & 2017 \\
\hline Iraque & $\begin{array}{l}\text { Aquisição da Bashneft, torna-se fornecedor } \\
\text { da Turquia }\end{array}$ & 2016 \\
\hline Líbia & $\begin{array}{c}\text { Cooperação da Rosneft e aproximação política com } \\
\text { um dos } \\
\text { maiores fornecedores de petróleo } \\
\text { à Europa }\end{array}$ & 2017 \\
\hline Armênia & $\begin{array}{c}\text { Controle da distribuição do país pela } \\
\text { compra da ArmRosGazprom, possibilidade de } \\
\text { vetar novas rotas para a Europa }\end{array}$ & 2006 \\
\hline
\end{tabular}

Fonte: Chow; Stanley (2018); Kommersant; RBC. 


\section{Universidade Federal Fluminense \\ Instituto de Estudos Estratégicos}

\section{DISCUSSÃo}

A sistematização de mecanismos utilizados pela política externa russa expressos neste artigo indicam que o setor de P\&G seguirá sendo um elemento central na grande estratégia russa, concentrada em três frentes: a Europa, a China e o estrangeiro próximo, visto como parte integrante da zona de influência russa e como região-tampão em relação às potências ao entorno.

Do ponto de vista geopolítico, a Rússia conseguiu tornar significativa a dependência europeia sobre o seu petróleo, que passa de 7\% em 1990 a 32\% em 2016. No que diz respeito ao gás, a Rússia viu esta dependência cair, porém, para níveis ainda assim muito altos, passando de $68 \%$ a $40 \%$ no mesmo período. Por outro lado, houve uma diversificação dos destinos das exportações. Estas, ainda reféns da demanda europeia, passam a ser realizadas em peso também para a China, e devem ser ainda mais diversificadas para o leste asiático (que vem ganhando crescente importância) uma vez desenvolvidas e expandidas as produções de GNL em Yamal e em Sakhalin II.

Já a situação do gás natural é a oposta: apesar de Moscou ter aumentado o volume exportado do combustível, Bruxelas tem conseguido diversificar suas importações. O faz aumentando as importações de Noruega e Argélia (os outros principais fornecedores) e estabelecendo novas rotas para absorver combustível do Cáspio (GOMES, 2018). O GNL pode vir a ser uma alternativa estratégica para a Europa, mas ainda não é tão competitivo quanto à infraestrutura de transporte já existente ao continente, de modo que representa pouco mais de 10\% das importações de gás natural (GOMES, 2018). Vale notar também que a UE soube manter, por hora, sua independência do gás americano, que, para a Europa, segue sendo desprezível, uma vez que esta recorre mais fortemente ao Qatar. Buscando se adaptar ao desafio do GNL, a Rússia desenvolveu produção na península Yamal (Ártico), projeto inaugurado no fim de 2017 (LNG WORLD NEWS, 2018) e vai atender os mercados da Europa e da Ásia, ao lado de Sakhalin II (TOTAL, 2018).

A alavanca energética tem se mostrado um mecanismo de pressão efetivo sobre os países do estrangeiro próximo. As antigas repúblicas da Ásia Central veem sua margem de ação expandir-se graças à disputa pelos hidrocarbonetos da região por três potências, a infraestrutura instalada em 


\section{Revista Brasileira de Estudos Estratégicos}

REST V13 No 25 Jan-Jun 2021

direção à Rússia, a própria importância do mercado russo e o caminho facilitado ao mercado europeu, fazendo com que o vizinho do norte siga sendo um destino central para as suas exportações.

No Cáucaso, a iniciativa europeia do SGC também reduziu a dependência de Azerbaijão e Geórgia frente a Moscou, ainda que a Geórgia siga pressionada pelo "conflito congelado" na Ossétia do Sul, que é ajudada em seus esforços de separação pelo fornecimento de gás da Gazprom. Na região, apenas a Armênia está perfeitamente alinhada com os interesses geopolíticos do Kremlin, mas desempenha um papel central na estratégia de impedir que o combustível iraniano integre o corredor à Europa.

A Ucrânia, por sua vez, será pressionada nos próximos anos pela bemsucedida estratégia russa de circulá-la. A capacidade combinada de transporte de gás à Europa dos gasodutos Yamal-Europa e os gêmeos Nord-Stream 1 e 2 é de 142,9 bcm, aos quais ainda falta o acréscimo fornecido pelo TurkStream. Uma vez que em 2016 o total de gás importado da Rússia pela UE foi de 153 bcm, Kiev se tornará irrelevante como rota de passagem, e seu fornecimento poderá ser interrompido. O cálculo do Kremlin é que isto pressione o suficiente seu vizinho eslavo para que este seja recolocado em sua zona de influência. $O$ interesse russo no país, além de sua importância simbólica em seu projeto geopolítico, está ligado à possível adesão ucraniana à OTAN, mesma situação da Geórgia. Espera-se que, consolidando a influência sob a Ucrânia e estimulando os conflitos separatistas tanto nela quanto na Geórgia, evite-se que estes dois países fronteiriços venham a integrar a aliança do Atlântico Norte (RADVANYI; LARUELLE, 2016).

Resta mencionar os novos desafios com os quais o Kremlin terá que lidar. Apesar dos esforços do governo Putin para diversificar as fontes de renda e exportação ${ }^{12}$, a economia russa segue dependendo excessivamente do petróleo e se mostra vulnerável a quedas abruptas do preço do combustível. Essa vulnerabilidade ficou clara desde o choque do petróleo, de 2014, que combinou um choque de oferta, devido ao crescimento abrupto da produção nos EUA, que não foi acompanhado por uma redução da produção da OPEP, com a

$12 \mathrm{E}$ o tem conseguido em alguma medida, uma vez que a receita russa vem crescentemente sendo providenciada por outros setores que não o energético (GOMES, 2018). Contudo, o país mantém uma forte dependência das exportações do setor. 


\section{Universidade Federal Fluminense \\ Instituto de Estudos Estratégicos}

desaceleração do crescimento chinês (LINS ET AL., 2015). Os EUA serão, de fato, um ator problemático para a Rússia na geopolítica do petróleo e gás a partir desta década, beneficiados pelas mudanças nos paradigmas tecnológicos aos quais o país eslavo precisa se adaptar. Por um lado, espera-se que os EUA sejam responsáveis por $80 \%$ do crescimento da demanda global por petróleo nos próximos anos (CUNNINGHAM, 2018), graças aos avanços na tecnologia de "Shale Oil". Pelo outro, a difusão do GNL - do qual os EUA devem se tornar em breve o maior produtor global (INTERNATIONAL, ENERGY AGENCY, 2017) - pode significar um enfraquecimento dos gasodutos como instrumento geopolítico, uma vez que, no caso do corte de fornecimento por via terrestre pode ser balanceado pela importação do gás liquefeito.

\section{REFERÊNCIAS}

BRITISH PETROLEUM. Baku-Tbilisi-Ceyhan Pipeline. Disponível em : < https://www.bp.com/en az/caspian/operationsprojects/pipelines/BTC.html>.

Acesso em: 19 nov. 2018b.

CHOW, Edward C.; STANLEY, Andrew J. Russia's National Oil Champion Goes Global.CSIS, 22 fev. $2018 . \quad$ Disponível em: $<$ https://www.csis.org/analysis/russias-national-oil-champion-goes-global>. Acesso em: 21 nov. 2018.

CUNNINGHAM, Nick. IEA Predicts Nightmare Scenario for OPEC. Oilprice, 05 mar. 2018. Disponível em: < https://oilprice.com/Energy/Energy-General/IEAPredicts-Nightmare-Scenario-For-OPEC.html>. Acesso em: 22 nov. 2018.

DELLECKER, Adrian. Caspian pipeline consortium, Bellwether of Russia's Investiment Climate? Russie.Nei.Visions, Paris, № 31, June 2008.

DUGIN, Alexander. Eurasian Mission. Arktos Media Ltd. [online], 2014.

EL FINANCIERO. China 'saca partido' de los precios bajos del petróleo y acapara demanda en medio de la pandemia. 26 abr. 2020. Disponível em: < https://www.elfinanciero.com.mx/economia/china-aprovecha-los-precios-bajosy-acapara-petroleo-en-medio-de-la-pandemia>. Acesso em: 27 abr. 2020.

EUROPEAN COMISSION. Gas and Oil Supply Routes. Disponível em: $<$ https://ec.europa.eu/energy/en/topics/imports-and-secure-supplies/gas-andoil-supply-routes>. Acesso em: 20 nov. 2018.

GAZPROM. “Газпром” полностью выполняет обязательства по газоснабжению потребителей Южной Осетии [“Gazprom” cumpre a totalidade das suas obrigações de fornecimento de gás para a Ossétia do Sul]. 62 jul. 2017.2 Disponível em: < http://www.gazprom.ru/press/news/2017/july/article340776/>. Acesso em: 20 nov. 2018. 


\section{Revista Brasileira de Estudos Estratégicos}

REST V13 No 25 Jan-Jun 2021

TurkStream.

Disponível

em:

$<$

https://www.gazprom.com/projects/turk-stream/>. Acesso em: 20 mar. 2020.

GOMES, P. H. M.. A Federação Russa (1991-2018): Petróleo e Gás, Instrumento Geopolítico e Desenvolvimento Econômico. 2018. Monografia (Graduação em Relações Internacionais) - Instituto de Estudos Estratégicos, Universidade Federal Fluminense, Niterói.

GORDONUA. B "Укртрансгазі" заявляют, что "Газпром" продолжает нарушать обязательства по давлению на входе в ГТС Украины [Em "Ukrtransgazy" afirma-se que a "Gazprom" continua a violar as obrigações de fornecimento na entrada do sistema de gás da Ucrânia]. 2 mar. 2018. Disponível em: < https://m.gordonua.com/news/money/v-ukrtransgaz-zayavlyayut-chtogazprom-prodolzhaet-narushat-obyazatelstva-po-davleniyu-na-vhode-v-gtsukrainy-234403.html>. Acesso em: 21 nov. 2018.

HYDROCARBONS TECHNOLOGY. South Stream Pipeline Project, Europe. Disponível em: <https://www.hydrocarbonstechnology.com/projects/southstream/>. Acesso em: 20 nov. 2018.

KARAKALPAKSTAN BLOG. Central Asia-Center gas pipeline system. 13 mar. 2017. Disponível em: <https://karakalpakkarakalpakstan.blogspot.com/2017/03/central-asiacenter-gas-pipeline-

system.html>. Acesso em: 21 nov. 2018.

KATONA, Viktor. Russia is Taking Over Syria's Oil and Gas. Oilprice, 14 fev. 2018. Disponível em: < https://oilprice.com/Energy/Energy-General/Russia-lsTaking-Over-Syrias-Oil-And-Gas.html>. Acesso em: 21 nov. 2018.

KHODAKOVSKYY, Yevgen. The legal framework of EU-Russia energy relations. 2013-2014. Dissertação (Mestrado em Direito) - Faculdade de Direito, Universiteit Gent, Gante.

KOMMERSANT. Армения переходит на "Газпром" [Armênia muda para Gazprom]. $\quad 7 \quad$ abr. $2006 . \quad$ Disponível em:< https://www.kommersant.ru/doc/664470>. Acesso em: 14 set. 2020.

LINS, Clarissa; MORAIS, Raoni; HOLLANDA, Lavínia. Uma Visão Geral da Indústria de Óleo e Gás na América Latina. In: KONRAD ADENAUER STIFTUNG. Geopolítica de Óleo e Gás na América Latina. Dezembro 2015.

LNG WORLD NEWS. Cedigaz: Europe's LNG imports slide in first half of 2018. 12 jun. 2018. Disponível em: < https://www.Ingworldnews.com/cedigaz-europesIng-imports-slide-in-first-half-of-2018/>. Acesso em: 22 nov. 2018.

MARCU, Silvia. La Geopolítica de La Rusia Postsoviética: Desintegración, Renacimiento de una Potencia y Nuevas Corrientes de Pensamiento Geopolítico. Barcelona: Scripta Nova, vol. XI, nํ253, 2007.

MONGRENIER, Jean-Sylvestre; THOM, Françoise. Géopolitique De La Russie. Paris: Presses Universitaires de France, 2016. 


\section{Universidade Federal Fluminense \\ Instituto de Estudos Estratégicos}

NEFTEGAZ. Merkel in clash with Poland over Russian Nord Stream 2 gas pipeline plan. 19 fev. 2018. Disponível em: < https://neftegaz.ru/en/news/view/169245-Merkel-in-clash-with-Poland-overRussian-Nord-Stream-2-gas-pipeline-plan>. Acesso em: 20 nov. 2018.

Pakistani minister: IP gas pipeline project still affected by sanctions. 14 jun. 2017. Disponível em: <https://neftegaz.ru/news/view/162015Pakistani-minister-IP-gas-pipeline-project-still-affected-by-sanctions>. Acesso em: 21 nov. 2018.

NYGREN, Bertil. Unilateral Endeavours Challenging Governance in the Energy Sector: Russia, China and the US. In: WAGNSSON, Charlotte; et al. European Security Governance: The European Unian in a Westphalian World. Abingdon: Routledge, 2009.

PIATIGORSKY, Jacques; SAPIR, Jacques. Le grand jeu: XIXe siècle, les enjeux géopolitiques de l'Asie centrale. Paris: Éditions Autrement, 2009.

RADVANYI, Jean; LARUELLE, Marlène. La Russie entre peurs et défis. Paris: Armand Colin, 2016.

RBC. Газпром подписал договор о покупке доли Армении в "АрмРосгазпроме" [Gazprom assinou acordo sobre a compra da parcela da Armênia na "ArmRosGazprom "]. 16 jan. 2014. Disponível em : < https://www.rbc.ru/economics/16/01/2014/570416019a794761c0ce5afe>.

Acesso em : 14 set. 2020.

REGNUM. EC готов обсуждать поставки иранского газа через Южный газовый коридор [UE pronta para debater o fornecimento de gás iraniano através do Southern Gas Corridor]. 16 fev. 2018. Disponível em: <https://regnum.ru/news/2381017.html >. Acesso em: 19 nov. 2018.

SCHUTTE, Giorgio Romano. Economia Política De Petróleo E Gás: A Experiência Russa. In: ALVES, André G. M. Pineli (org). UMA LONGA TRANSIÇÃO: Vinte Anos de Transformações na Rússia. Brasília: IPEA, 2011.

SOUTHERN GAS CORRIDOR. South Caucasus Pipeline. Disponível em: < https:/www.sgc.az/en/project/scp >. Acesso em: 19 nov. 2018.

STRATFOR. The Strategic Importance of the Caspian Sea. 19 mai. 2014. Disponível em: <https://worldview.stratfor.com/article/strategic-importancecaspian-sea>. Acesso em: 19 nov. 2018.

TOTAL. Yamal Lng: The Gas That Came In From The Cold. Disponível em: < https://www.total.com/en/energy-expertise/projects/oil-gas/lng/yamal-Ing-coldenvironment-gas >. Acesso em: 22 nov. 2018.

TRANS ADRIATIC PIPELINE. Project Progress. Disponível em : < https://www.tap-ag.com/pipeline-construction/project-progress>. Acesso em: 19 nov. 2018. 
VESTI. "Газпром" и "Нафртогаз" обсудили расторжение договора [Gazprom e Naftogaz discutiram o cancelamento dos acordos]. 27 mar. 2018. Disponível em : < https://www.vestifinance.ru/articles/99470>. Acesso em: 21 nov. 2018.

YAKEMTCHOUK, Romain. La politique étrangère de la Russie. Paris: L'Harmattan, 2008.

YERGIN, Daniel. A BUSCA: Energia, segurança e a construção do mundo moderno. Rio de Janeiro: Intrínseca, 2014.

ZARUBIN, Pavel. "Мы Выучили Уроки": Самая Послушная Страна EC Извинилась Перед Москвой ["Nós aprendemos a lição": País Mais Obediente da UE de Desculpa Frente a Moscou]. Vesti, 30 mai. 2018. Disponível em: <https://www.vesti.ru/doc.html?id=3023067\&cid=5>. Acesso em: 20 nov. 2018. 